\title{
The Impact on Public Health and Economy Using Lockdown as a Tool against COVID-19 Pandemic in Africa: A Perspective
}

\author{
Richard Owusu Nyarko ${ }^{1, *}$, Edward Boateng ${ }^{2}$, Ivan Kahwa ${ }^{3}$, Paul Owusu Boateng ${ }^{4}$, Rosemond Owusu Nyarko ${ }^{5}$, Bertram Asare ${ }^{6}$ \\ Christian Asum ${ }^{7}$, Grace Ama Ampong ${ }^{8}$ and Daniel Azumah Nayembil ${ }^{9}$
}

\author{
${ }^{1}$ Department of Health management, School of Graduate Studies, Ghana Technology University College, Ghana \\ ${ }^{2}$ Department of Surgery, Komfo Anokye Teaching Hospital, Ghana \\ Science and Technology, Mbarara, Uganda \\ ${ }^{4}$ School of Medicine, Medical University of China, Jinzhou, China \\ ${ }^{5}$ Department of Surgery, Neurology Intensive Care Unit, Korle Bu Teaching Hospital, Accra, Ghana \\ ${ }^{6}$ School of Medicine, American International University of West Africa, Banjul, Gambia \\ ${ }^{7}$ School of Business, Presbyterian University College, Abetifi Kwahu, Ghana \\ ${ }^{8}$ Faculty of Health and Medical Sciences, Presbyterian University College-Asante Akyem Campus, Agogo, Ghana \\ ${ }^{9}$ Graduate School, York University, Canada
}

${ }^{3}$ Department of Pharmacy, Faculty of Medicine, Pharm-Biotechnology and Traditional Medicine Centre of Excellence (ACEII), Mbarara University of

*Corresponding author: Richard Owusu Nyarko, Department of Health management, School of Graduate studies, Ghana Technology University College, Accra, Ghana, Tel: +233266884732; E-mail: richardnyarko91@yahoo.com

Received: 23 Apr, 2020 | Accepted: 15 Jul, 2020 | Published: 22 Jul, 2020

Citation: Nyarko RO, Boateng E, Kahwa I, Boateng PO, Nyarko RO, et al. (2020) The Impact on Public Health and Economy Using Lockdown as a Tool against COVID-19 Pandemic in Africa: A Perspective. J Epidemiol Public Health Rev 5(3): dx.doi.org/10.16966/2471-8211.188

Copyright: (C) 2020 Nyarko RO, et al. This is an open-access article distributed under the terms of the Creative Commons Attribution License, which permits unrestricted use, distribution, and reproduction in any medium, provided the original author and source are credited.

\section{Abstract}

Background: Since the spread of Corona Virus Disease 19 (COVID-19) most African countries have embarked on a system of either total or partial lockdown and have used it as a tool for curbing the spread of COVID-19. This study examines whether lockdown can be of help and whether it is any of the public health policies that can bring massive and tremendous change to health systems and general economy of African countries using it as a way of intervention to curb the spread of COVID-19.

Method: The researchers reviewed some literature about world economies with Google as the main search tool. They also listened to press conferences, editorial reviews from the African Union, World Bank, International Monetary Fund, and the World Health Organization. Interviews were also done through phone calls, questions asked via emails to some of the world's leading epidemiologists, infectious disease specialists in the United States of America, Europe, Africa, and some of the listed countries in their work.

Results: After a careful study and analysis of countries like Hong Kong, South Korea, Japan, Singapore, Taiwan who did not really make lock down as a major measure in fighting the COVID-19 disease still saw a stable economy, a drastic containment of the pandemic, few deaths and more recoveries as compared to countries in Africa like south Africa which is the worst affected African country, Nigeria, Morocco, Egypt, Kenya, Ghana, Uganda, the Gambia, Sierra Leone, Senegal that embarked on massive lockdown either partially or completely but still showing plummeting inflation, declining gross domestic product, loss of capital for business groups, loss of jobs especially in the informal sectors, (negative growth with Ghana an exception) due to disruption of the world economy through global value chains, abrupt fall in commodity prices and fiscal revenues and enforcement of travel and social restrictions all due to the COVID-19 pandemic.

The researchers found that a total lockdown without Mass testing which is best or symptomatic testing for countries with fallen and weak economies since mass texting is capital intensive, Contact Tracing and Treating that are strongly interspersed with Public and Community health education and health campaigns through the mass media in both international and local dialects, all efforts of lock down become a zero or empty and defective process and this shows that lock down is no cure, has never been a cure, and shall not be a cure to the COVID-19 pandemic and any other future pandemics.

Conclusion: The researchers think that it is time public health systems of African countries are strengthened with befitting budgets, human resource developments of all kinds of cadres in the health and economic sectors, more public health educators should be recruited to use the mass media be it local radio stations, television stations, internet to educate the masses in their local dialects for better understanding on the effects of COVID-19 pandemics on respective countries, precautions, preventions and safety steps to follow even when one is suspected to have been infected with the disease. It is now time for African countries to adapt tailored measures in fighting the COVID-19 pandemic putting into consideration their culture diversity, local economies, climatic conditions, availability of resources and funds and only use the World Health Organization's guidelines as a bench mark while African economies try to emulate from the pacesetter countries like Japan, South Korea, Hong Kong, Taiwan that have been able to contain the spread of COVID-19.

Keywords: COVID-19; Pandemic; Lock down; M3T; 2SQ; Economy 


\section{Introduction}

The purpose of a lockdown is intended to stop people from moving between places, it could also mean putting data in place to record the movement of people from place to place in a particular location. Lockdowns could involve canceling of flights both domestic and international, closing borders, closing shops, restaurants, schools, churches, etc., with the main idea by governments to reduce the influx of people to stop transmission of disease.

Almost all the African countries are inadequately prepared to deal with the exponential spread of COVID-19 with its pseudo recovery and recovery rates and Ghana is no exception. Most African countries have weak policies to combat pandemics coupled with weak health systems and scanty resources. Restriction orders from governments seems to most African governments as a major tool and intervention to stop COVID-19 but these measures have severely brought about economic and spatial inadequacies to African countries as the COVID-19 pandemic seems to have no ending time.

\section{Basic epidemiology and statistics}

The number of COVID-19 cases worldwide as of time of this research paper published stood at about 14 million with about 7 million recovered and about 550,000 deaths. Cases in Africa have quickly risen to more than half a million and the death rate exceeds about 12,400 with about 270,000 recoveries and this can be termed extremely alarming. African countries like Ghana have about 23000 cases, about 135 deaths and about 17,500 recoveries. Uganda has about 1200 confirmed cases, about 1000 recoveries and zero deaths, Senegal has about 9000 confirmed cases, about 5300 recoveries and about 150 deaths, Nigeria has about 33000 confirmed cases, about 13500 recovered and about 710 deaths.

South Korea had about 50 new cases and one death, Japan had about 220 new cases and only one death. Taiwan had about 11 new cases and no death, Hong Kong had about 48 new cases with no new death, Singapore has about 128 new cases with no death, Thailand has about 5 new cases with no death, Switzerland had about 93 new cases with no death [1].

This free rise and sudden increasing high death rate in the African continent but with more numbers of confirmed cases should tell us that Africa is now stepping up policies and implementing good measures and improving the rate of COVID-19 testing. This can still be fatal if proper public health interventions are not put in place and in order to get the best practices of public health interventions, a country needs the capital or income, many trained health personnel, infrastructure as in treatment centers and isolation centers, special hospitals for such purpose as in infectious disease centers with state of art tools and equipment.

According to the World Health Organization, African continent has just 1.06 nurses and midwives for every 1000 inhabitants and this show how porous and weak our health systems are. Since the spread, many African countries have put in measures to help respond quickly to the pandemic and Ghana falls within the best practices of such $[2,3]$.

\section{Socio psychodynamics of African nations}

The inability to produce the basics needed to support life makes life unbearable and it is an undeniable fact that Ghana and many African countries have many deprived and vulnerable social groups that always struggle to feed and care for their immediate and extended families that is even if all conditions are well and favorable. So in this pandemic era where there are total and partial lockdowns with restriction orders on trade and industry and movement, it becomes dire and extra difficult for such groups and apart from the socio-economic impact, the adverse effect in terms of psychological and emotional is heavier when all are home and the little money saved as emergency life fund or life insurance is been used for feeding and care making such people weaker when exposed to life's eventualities like debilitating sudden illness, road traffic accidents, flooding, etc. There are some research works done in the UK by researchers at imperial college estimating that under the most optimistic circumstances the coronavirus would kill 300,000 people in sub-Saharan Africa and such research works should be a pain to African leaders and government [4,5].

\section{Economic woes of African countries during this COVID-19 pandemic}

The government of Ghana and most African countries have imposed restrictions on imports and exports, closed both international and local borders with neighboring and afar countries, supply and procurement chains disrupted, most industries and production companies have halted operations and such shall have a serious and dire effect on general inflation and gross domestic product with Ghana, not an exception. According to the African Union, up to 20 million jobs in the formal and informal sectors in Africa could be lost because of COVID-19 and Ghana have had a high level of unemployment rate before this COVID-19 pandemic so making the case worse for the workforce of Ghana and other African countries currently.

A study released in April 2020 found that Foreign direct investment (FDI) be it tourism receipts and remittance flows will suffer significant declines as the continent tackles this pandemic. If this pandemic stays for 5 months or more then the tourism industry in Africa will suffer the worse and Ghana, Uganda and Gambia are countries that dwell much on tourism especially revenues from tourist sites, hotels, etc.

In a research titled the impact of coronavirus on African economy conducted early April 2020 shows that if the pandemic lasts for 5 to 7 months there would be a negative growth due to disruption of the world economy through global value chains, abrupt fall in commodity prices and fiscal revenues and enforcement of travel and social restrictions. Further to the study, the African Union has also stated that a 35\% dip in exports and imports would be worth $\$ 270$ billion, yet Africa will require $\$ 130$ billion to fight against the spread of the virus and medical treatments.

Many African countries have taken bold steps to salvage their people and economies but the approach by the government of Ghana during this COVID-19 pandemic supersedes most and is the most actionoriented. The Ghana government has been taking experts advice and opinions, collaborating with the World Health Organization, the country's ministry of health, Ghana health service and other agencies and has urgently designed and implemented ambitious, well-informed policies to help the citizenry and the general economy with steps such as 3 months free utility bills of water and electricity for every citizen in Ghana during the month of Aril, May and June 2020, tax exemptions for frontline health workers of COVID-19 pandemic, life insurance for frontline health workers who may be devastated by of COVID-19 in their line of service, increased pay rise and special incentive allowance for three months for some health workers starting April 2020 and if most African leaders exhibit such leadership style then Africa can stand firm and tall in these hard times of the pandemic [6,7].

\section{How proactive are African leaders and governments towards science and technology}

African leaders were to learn effectively from the Ebola epidemic in 2014 and were to design strong policies and set up budgets for 
emergencies, set up well-equipped research laboratory centers for infectious diseases in many parts of their countries, employ more medical research scientists and create budgetary funding for such purposes. If these were done then Ghana and most of her sister countries at this time would be and shall have the human resource, the ability to undergo mass testing and dynamics of treating suspected and confirmed cases, creating of temporal immediate methods of helping deal with this pandemic.

Most governments in Africa tend to concentrate more on political goals and points than science and technology and this is the fall of Africa and the deficit it creates when natural disasters and disease pandemics like COVID-19 occur.

All is not lost and as African countries and governments suffer, most may, can and should learn from this COVID-19 pandemic and give more room for science and technology to prevail to develop Africa as a whole and more especially countries like Ghana, Nigeria, Morocco, Senegal which are some of the leading countries in Africa with more COVID-19 confirmed cases.

Ghana per se is one of the luckiest African nations now especially in the fight of COVID-19 pandemic since the immediate past president has formed a supplementary team to support the citizenry through public education, sharing and distributing person protective equipment (PPEs), medical consumables, cash donations, food, etc., to accredited facilities and deprived communities. Ghana is again lucky since the other two surviving former presidents are also keen in supporting the incumbent governments' course of making Ghana defeat this pandemic. They have all done well with sharing their experience as former presidents, advice and involved in the donations to deprived communities especially in the time they are needed most and this trait is worth emulating and precedence for world leaders [8].

\section{Global health dynamics in containing COVID-19 with Africa lifting its lockdown}

Ghana has lifted her local and internal borders of intercity, inter towns, inter suburbs for free and easy trade, access to health care, access to banks and access to pay bills, opening churches, mosques, and schools which usually are known places worldwide for close contact and crowding but with laid down protocols on prevention to follow. Markets are opened but with scrutiny for buyers and sellers to have the approved spacing interval of 1 to 3 meters. This is a pragmatic and good step and West African countries should emulate it since in the middle of the pandemic there can still be room for emerging economies to augment and better their health systems and general economy.

This is not new and can be effective to curb the continuous spread and improve the local economy when persons respect and adhere to preventive guidelines from the World Health Organization, various African ministries of health and government policies. The ministry of health and ministry of information Ghana, the Ghana health service advises on staying at home when outing is not urgent and of emergency, washing hands under running water with soap, applying alcohol-based hand sanitizers.

The use of face mask and not face shield when going out and even in the comfort of their homes especially for those living in commercial houses and apartments and flats that share car parks, gymnasium, etc.

The researchers see the need for African governments to create way for local industries to make their own face masks giving them support and tax exemptions whilst they follow regulatory standards of various standard agencies and food and drugs authorities as pertained in various countries.

Ghana lifting her lockdown is a bold decisive step to open up for domestic trade and it will improve the local economy and also improve the spread of COVID-19 if Ghana learns from pacesetter counties who aggressively tackled the COVID-19 pandemics without any lockdown and heavy restrictive orders on the citizenry. Government of Ghana and African countries may still have the opportunity to lock down some cities, towns, districts, regions or provinces when the need be were cases are rampant based on advice from epidemiology and disease control experts, public health experts, economists etc. A total lock down of a whole country has no benefit economically and also health wise since people need free fresh air to fight air borne diseases like COVID-19.

There are pacesetter countries like Japan, Taiwan, Singapore, Hong Kong, Switzerland, South Korea, Thailand who did not go for total locked down domestically due to the pandemic and only did systemic lock down to cities, towns or districts that had many new cases, and Ghana can learn from them. Although these are big economies or developed countries with better and stronger health systems, Ghana can still learn their basics of interventions, policies and implement same to contain the COVID-19 pandemic [9].

\section{The Asian giants (South Korea, Singapore, Japan, Hong Kong,) style of containing the COVID-19}

South Korea as of March 25, 2020, had about over 9000 cases of COVID-19 confirmed cases that placed them among the top 10 countries for total cases but the country managed recently to significantly slow the number of new cases without taking in strict lockdown measures and draconian orders. These countries have been able to make tactical decisions on schools, movement, etc. They embarked on mass testing and tested widely for the virus, isolated cases, and quarantined suspected cases and the same way did Singapore also do and these two countries managed to suppress transmission of the virus. South Korea developed testing kits for the coronavirus even before it had a significant number of cases.

Health authorities of South Korea conferred with research institutions to develop a test kit and after it was done it was shared with the potent pharmaceutical companies to develop and produce reagents and equipment needed for the testing.

Such practice shows that testing is central to the outbreak response and without testing there will be no early detection and catastrophe can set in. Hong Kong after seeing the success of South Korea, Singapore also joined and implemented the same strategies and policies to defeat the corona virus disease 19.

The approach by these Asian giants (South Korea, Hong Kong, Singapore, Japan) made the World Health Organization's directorgeneral refer to the strategy as cutting off the virus from the bud, meaning stopping the virus from spreading further and preventing community transmission.

These countries have been able to keep most of their factories, malls and restaurants opened and Singapore has even kept schools opened at a time when nations around the world are shutting down classrooms.

There is little evidence to show that schools should be closed down in these Asian countries since the young vectors or spreaders of the COVID-19 are not evidenced-based.

South Korea has used data from surveillance cameras, cell phones, and credit card transactions to map the social connections of suspected cases. 
Hong Kong doesn't give out the names of those infected; health officials release each person's age, gender, street address, medical symptoms, and often the exact location of where the person works.

This allows other residents to determine if they might have been in contact with the infected individual. The health department of Hong Kong also releases license number plates of taxi drivers who test positive and the flight numbers of infected travelers who arrive so members of the public can determine if they might have contact. In Singapore, the police force works with the ministry of health to trace connections between cases and to track chains of transmission. Singapore also makes details of these infections' public in the hope that other residents will come forward if they may have come in contact with a confirmed case.

"The aggressive efforts by the Asian giants (Hong Kong, Japan, Singapore, South Korea) to investigate and isolate every possible infection may be and could be exactly what the World Health Organization has been calling for since January 2020 but the World Health Organization according to the writers of this research may and could have failed to know that such aggressive methods are driven by financial stability and clean financial sheets and deficit free budgets from individual countries and most African countries are at the verge of diminishing returns and overridden debt from developed countries and may not have the financial capacity to embark on such aggressive and technologically driven methods as used by the Asian giants" [10].

\section{Taiwan style, the Asian country that is not a member of the World Health Organization}

Taiwan has a population of about 24 million people almost the same as Australia and yet they have less than 400 cases of COVID-19 while Australia has an excess of 500. Taiwan has been able to keep the virus under control when other parts of the world have not been able.

This is a matter of hard lessons learned during the severe acute respiratory syndrome (SARS) outbreak in the year 2003 which Taiwan was one of the most affected worldwide along with Hong Kong and southern China.

Asia has the most preventive and secured response to the coronavirus by border controls, wearing of the face masks, and making it a routine in early January 2020.

Taiwan has a world-class health care system with universal health coverage. As the news of COVID-19 began to emerge Taiwan national health command center (NHCC) moved in to respond quickly to the potential threat (Journal of American Medical Association).

Taiwan rapidly produced and implemented a list of at least 12 action items in 5 weeks to protect the public health and their policies and actions went beyond border control because to them it was not enough. Although Taiwan was at greater risk for COVID-19 due to its proximity, ties, and transport links outside mainland China.

Among the early decisions of Taiwan was to ban travel from many parts of China, stop cruise ships docking at the island ports, and introduce strict punishment for anyone found breaching home quarantine orders. Further to that, Taiwan officials moved to ramp up domestic face masks production to ensure the local supply.

Taiwan rolled out island testing for the coronavirus including retesting people who had previously had unexplained pneumonia, also, it announced punishment for those who may spread false information about the virus and COVID-19.

A common platform was made an avenue for well trained and experienced teams and cadres of health care to address the emerging outbreak; however strict lockdowns that characterized the response in China and many other countries were so much avoided.

Taiwan also avoided the type of "Taiwan is not a member of the World Health Organization" hence they are always planning, making policies, and implementing strategies that far advance the world health care practices.

\section{Ghana as an example in Africa for others to emulate}

Ghana has opened up its domestic trade in this pandemic, it is time the government collaborates effectively, open up for expert advice, and continue to mobilize experts from the local settings and abroad to find solutions and also draw closer to the World Health Organization.

This is the time political leaders, government in power should do all they can and not to use excessive powers or abuse or force on citizenry even if some go contrary to regulations but rather use the time to educate such people and continuous defaulters or recalcitrant persons brought to book with punishments that can help the environment like weeding, cleaning, desilting gutters, sweeping streets and fines that can be paid to governments to add on to monies needed for COVID-19 prevention campaigns.

Political leaders should know that this COVID-19 pandemic is a public health crisis and all should come together to help find proper and better solutions and remedies to this course and incumbents' governments occasionally should allow itself for checks and balances.

African countries will continue to borrow from the World Bank, the international monetary fund and other monetary agencies to augment their reserves to stabilize their shaking economies at this critical point of the COVID-19 pandemic.

These basics of accountability and loyalty to the ordinary citizenry and the donor agencies can be done through state of nation addresses, press briefings, through a complete breakdown and dissemination of information to the ordinary citizen through the various ministry of information or ministry of communications in both local dialects and international dialects.

A critical observation, analysis, and trend monitoring have so far shown that the Current government of Ghana has been doing well and all must encourage, back and support the incumbent government's good initiative of making the ordinary citizenry and Ghana know how much they are spending and the dire financial crisis this pandemic has to be fallen on Ghana.

Further to Ghana lifting the lockdown on the domestic or internal market and economy, the country cannot stand firm only on such measures and the economy for this period shall continue to fall and dwindle since Ghana's main source of income falls on export commodities which bring in foreign exchange and is a benchmark for foreign exchange liquidity that can ease balance of payment constraints and as a source of employment for the many youths. Such an intervention or initiative would help and keep the ordinary Ghanaian and their families stable although the macro economy may suffer; it brings peace and stability within the country to avert any form of tension and aggression among the citizenry and between the governments of the day.

This is a good start for Ghana and is a clarion call for African countries especially those in the west to emulate Ghana and adapt most of the policies and interventions the current government has kept in place for the benefit of citizens and the progressively steady tactics of fighting the COVID-19 pandemic although Ghana has a long way to go and a lot to put in place to achieve the optimum [10]. 


\section{School health services}

According to the World Health Organization, school age children spend one third of their time in schools. Schools therefore constitute a unique setting to help children and adolescents to develop a positive outlook on life and help them establish healthy lifestyle. Yet global mortality and morbidity estimates in children and adolescents suggest that school aged children have significant needs for health promotion, prevention, and health care services $[11,12]$.

\section{Strengthening of school health boards}

School health services or boards are part of the whole school approach that is promoted by the World Health Organization through global school health initiative launched in 1995. The initiative supports countries to implement the four pillars of health promoting schools:

a) Health promoting school policies

b) Safe and healthy school learning environment

c) Skills based health education

d) School based health and nutrition services

For any developing or progressing economy to attain and achieve its great height, it needs education since it is the backbone for future leaders. The education sector for most developing economies shall be affected by the pandemic and schools may be closed from basic to tertiary level.

It is believed that schools are one of the places were overcrowding occurs and the preventive measure of social distancing of 1 meter would not be adhered to, also there may be indiscriminate coughing and sneezing by students and this can cause a free rise of COVID-19 when infection sets in but there are no grounded and limited scientific data or research to show that transmission of COVID-19 becomes rampant in schools or schools are the fertile transmission ground for COVID-19 disease [13-15].

According to the global accelerated action for health of adolescents (AA-HA) recommends that every school should be a health promoting school $[11,16]$.

With such no strong scientific and empirical data on COVID-19 transmission in schools, African countries with scanty resources, logistics, and infrastructure in their education sectors may have to strategize well and put basic measures in place in other to make schools progressive.

There is the need for governments and education ministries of African countries during this COVID-19 crisis to make policies and implement the setting up school health boards or school health services from their regional to district levels to advise, monitor, track and help treat suspected cases of COVID-19 in the various schools in order to sustain the education sector, especially schools. The organization of health assessments by preventive health services focusing on children health and educational performance needs to be improved due to evolving health priorities such as mental health problems, reduced budgets and shortages of health care professionals especially medical doctors and specialized nurses in African countries [15,17].

It would still be proper if all schools at this crucial time get a sick bay with a registered nurse and physician assistants who will manage suspected cases and quickly call in medical doctors or COVID-19 teams mandated by various governments to take over when such cases proof positive [15].

For schools to continue to open and operate, all students should continue to use the general public health education of face masks, hand washing, hand sanitizers which should be subsidize by African governments. Sitting positions in various schools should be made possible for the 1 meter apart distance in other to prevent indiscriminate touching and playing.

Further to the above, the teaching and non-teaching staffs should be mandated to wear face mask, follow all guidelines on prevention and reporting students who feel sick to the school nurse or any health professional in charge of the school's clinic or sick bay.

Also in such critical time, it may be very necessary and helpful if African governments through their various ministries of education could limit the learning hours of schools in order to avoid frequent break hours for playing and socialization, at least 2 to 3 hours of classroom work a day should be enough for students in such a pandemic season.

\section{Antibody antigen test kit for COVID-19 for all schools}

This should mean that African governments should ensure and make way for antigen and antibody COVID-19 test kits available in all school clinics or sick bays since such test is easy to be carried by any health professional and it takes 10 to 20 minutes for results to either show POSITIVE or NEGATIVE. Positive cases with the antibody or antigen test kits shall then be quickly be sent to accredited isolation centers for further testing where a polymerase chain reaction (PCR) TEST could be done to affirm diagnosis of COVID-19.

\section{Face shield cannot be compared to a face mask for COVID-19 prevention}

Since COVID-19 is an air borne disease, the use of face mask is key anywhere one find himself or herself, more education should be given on the care of face mask and people should be educated not to use face shields in place of face mask since face shield has no protection for air borne diseases.

Although face masks are awkward, uncomfortable but is very helpful in preventing COVID-19 and numerous research findings have shown that face mask especially the standard rectangular surgical mask will decrease the risk of infection to the person wearing the mask by $65 \%$ and that of the home made face mask could also achieve a little below $65 \%$ which are all good and better option than face shield which usually protect one's self from some amount of pathogens especially the whole face and also from chemical or organic splashing in industry and laboratory settings [18].

Face masks mainly provide physical barrier to respiratory droplets that are about one third the size of a human air and these droplets are one of the major ways the virus is transmitted. Studies in laboratory conditions show the virus stay in aerosol form with half-life on scale of hours and persist in the air and that is why it becomes a public health issue if people stay outside for social interactions. Enclosed places like bars, eatery, cafeteria become dangerous because the louder one speaks the more expiatory aerosols one puts out $[18,19]$.

\section{The M3T (Mass Testing Tracing and Treatment)}

In the M3T, $\mathrm{M}$ stands for mass, $1^{\text {st }} \mathrm{T}$ for testing, $2^{\text {nd }} \mathrm{T}$ for tracing and the last $\mathrm{T}$ for treating or

Mass Testing: Although there has been a lift on the domestic or internal lockdown, there is still a higher need for mass texting especially as data made available shows levels of community spread. This will yield results since external borders with neighboring countries are closed.

In as much as the government is helping, it would be better if rapid 
test kits that can bring results within 10 to 15 minutes are procured from world-renowned laboratories and bioscience centers to augment testing although scientifically is proven that the polymerase chain reaction test (PCR) is the most reliable. Abbot and cellex of the United States have passed through approvals from the food and drug authority of the United States of America to bring such kits to the market and averagely cost around \$ 6 per kit [20]. Another research institute in the state university of new jersey has gained approval from the food and drugs authority of unite states on their new biomaterial collection approach called the UUCDR infinite biologics to determine SARS $\mathrm{CoV}-2$ corona viruses.

This is a new saliva method which will allow broader population screening than most methods used as the nose and throat swabs. Most of the testing methods are done by performing nasopharyngeal or oropharyngeal collections and usually put health care professionals at risk although they put on PPEs so the new invention of saliva testing may go a long way to help.

In developing economies in Africa like Ghana, Nigeria, Senegal, Sierra Leone, Liberia, Gambia, Uganda, Tanzania, Burundi, Côte d'Ivoire, Togo, etc., with huge and always increasing population, it becomes a huge financial constraint for the governments due to their unstable economies yet the need to procure such fast and modern methods of testing for COVID-19 since it is over important purpose and for such a time and season. Further to that African governments need to recruit more public health and laboratory personnel to embark on such a continuous process looking at the population and it becomes another budget and unplanned cost yet vital to achieving success in the fight of COVID-19 pandemic.

In West Africa, Senegal was the first country to tailor COVID-19 protocols to suit their culture and diversity in tandem with the World Health Organization general international guidelines.

Senegal has been able to put safety measures in place and local scientist in collaboration with partners developed a COVID-19 test kit for trials and made easy and affordable at 1 US dollar per kit and produces results within 10minutes and they have done this in reaching rural populations to curb the biggest challenges to achieving widespread.

The kit has antigen and anti-body test, the antigen test can detect protein fragments of the coronavirus from nasal swabs or saliva whereas the antibody tests use tiny blood samples to detect signs of prior viral infection.

This has been very necessary since a vaccine for COVID-19 needs billions of dollars, rigorous safety stands and protocols, ethics standards and all these takes many years to achieve. According to the World Health Organization, the lack of coronavirus tests is now one of the biggest problems on the African continent. Kenya for example as of the month of May 2020, had only been able to test 1000 samples per day whereas laboratories in Germany were able to test more than 15000 per day according to Rocbert Koch Institute [21].

In Ghana, the Kwame Nkrumah University of Science and Technology (KNUST) together with Incas Diagnostics has developed a rapid diagnostics COVID-19 test kit which initial reports shows detects the COVID-19 antibodies in 20 minutes. It is a serological test which use a finger prick blood and in lateral flow format similar to blood glucose test or home pregnancy test. All is set but undergoing strict regulatory checks from the food and drugs authority in Ghana.

Tracing: Tracing of contact persons in the population has been very relevant since there is community spread. Without such a process the number of cases may go uncontrolled and the country can collapse. The social care system of Ghana and most African countries are weak and interspersed by culture, tradition and family ties and this makes the contact tracing very important since infected individuals unknown to them keep spreading the virus in their day to day interaction with loved ones, friends and families which they may also add up to spreading with other friends, relatives and in their line of business. This also needs human resources looking at how varied such practice is and calls for another unbudgeted cost by the government.

Treatment: Treatment now becomes key, when persons infected, are identified. This can only be done in accredited centers for such purpose. The fewer the cases the better for our lives endowed treatment centers and the efficient management of infected persons by the health care professionals.

If the number of cases goes higher than the need for more accredited centers to be established and more health care professionals recruited with expanding need for medical consumables and this becomes another headache for African governments since it is a financial burden and an unplanned budget.

\section{The 2SQ (social distancing, self isolation, quarantine)}

In the $2 \mathrm{SQ}$, the $2 \mathrm{~S}$ stand for social distancing and self-isolation while the $\mathrm{Q}$ stands for quarantine.

Social distancing: Social distancing purposely is to decrease the transmission risk. It usually stats with bigger groups of people like churches, mosques, schools, football games. It becomes necessary when one avoids all non-essential activities. One must avoid contact with persons and maintain a 3 meters part distance to any time when near people. The very point of social distancing is to prevent those numbers from going up and actually to flatten the curve of infections over time. Nonetheless, since the COVID-19 is an airborne disease and despite the social distancing, it will still infect people.

Self-isolation: Self-isolation is basically for people who have come into contact with infected persons or someone who has lived in or returned from a country with more cases of COVID-19. Such individual usually do not show symptoms but is a kind of precautionary measure and they should avoid staying out of home, limit physical contact with others and avoid petty transits.

They should then be educated on the symptoms and they monitor themselves for respiratory symptoms so sneezing, coughing, fever, and shortness of breath.

Quarantine: This comes into operation when persons have been tested for COVID-19 and waiting results or have tested positive for COVID-19. Such persons are usually confined to accredited centers or kept home in a prepared place and all is done to prevent them from getting into contact with others as much as possible [4,22-25].

\section{Conclusion}

In as much as the COVID-19 is fatal and a global health crisis, it is also a global security threat and there should be an opportunity for African leaders and governments to take bolder, more pragmatic steps to secure and shield supply chains of essential products be it consumables and non-consumables, strive harder to contain the health crisis, strive harder to maintain the stability of their financial systems, help businesses survive even in the crisis, support households, economic welfare of citizens, immigrants and there should be a way to compensate with stimulus package to reverse the economic damage the COVID-19 crisis has caused and still causing since there is not cure yet. 


\section{Recommendations}

a) As African countries always have ailing economies, the international monetary fund and World Bank should try as a matter of relief to give long span loans with little interest to severely affected African countries with this COVID-19 pandemic looking at its devastating effect on the world economy.

b) Although developed world has also been severely affected by the COVID-19 pandemic, the culture and diversity of citizens and immigrants as regulated by well-tailored measures and the stable and better health systems shall let them be able to control the pandemic well and open up.

c) This basically means developed world would soon put their economies back to shape while African countries continue in their bid to contain the pandemic with lock down (although not a major public health policy) and to screen suspected symptomatic and asymptomatic persons bringing huge financial budget to African governments and this is the time developed countries should re -consider waiving off debts of severely shaken African countries with the COVID-19 pandemic since at this crucial time debt relief is indispensable especially when imports and exports are hard hit with severe restrictions in most African countries.

d) The researchers advise the extremely important need for social distancing, self-isolation and quarantine, and maybe international boundary lockdown when the need be but including individual districts, regions or provinces when scientific data shows suspected or confirmed cases are on the high rise or above agreed border lines.

e) Another important point is that people should use face mask not face shields since face shield does very little scientifically to prevent air borne diseases and COVID-19 is an air borne disease. There should be community health education on the effective use of face mask rather than face shield since studies have shown that face mask especially the rectangular surgical mask cuts the risk of the person wearing it to about $65 \%$ preventing them from getting the COVID-19 infection.

f) The researchers see it as inevitable and a must do at this stage to forget mass testing which is a high expenditure, probable optimum approach for all countries but for developing world especially Africa, some parts of Asia, some parts of Latin America which are usually characterized with sinking economy, poverty and budget deficits.

g) With such countries a method of symptomatic testing although not the best can be employed to save finances, cut cost and prevent over burdening governments, health workers and the health systems in such developing economies. Contact tracing of persons who have been in touch with suspected or confirmed person of COVID-19 and treatment with laid down guidelines is a major tool and approach for saving such situation. These practices have been an effective, result oriented public health interventions. Border or boundary closure be it local or international and lock down be it part of country or whole country without Mass testing, Tracing and Treating interspersed with Public and Community health education and health campaigns through the mass media in both international and local dialects becomes a zero or empty and defective effort.

h) The researchers think is time African countries do as much as they can to emulate the aggressive approach the Asian giants (Singapore, South Korea, Japan, Hong Kong, Taiwan) took through with their health care system and also the process, policies, strategies and implementation done to bringCOVID-19 pandemic to the barest minimum as against the rest of the world.
Finally, the researchers recommend the setting up of school health services in all schools to promote health for students. It is time all schools have sick bays and school clinics with at least a physician assistant and a registered nurse permanently to help deal with the basic health conditions and needs of students, teaching and non-teaching staffs of these schools to help contain sudden health emergencies.

\section{References}

1. Corona virus disease statistics: Wikipedia 2020.

2. World Health Organization (2020) Coronavirus disease 2019 (COVID-19): situation report 70. WHO, Geneva, Switzerland.

3. Adhikari SP, Meng S, Wu YJ, Mao YP, Ye RX, et al. (2020) Epidemiology, causes, clinical manifestation and diagnosis, prevention and control of coronavirus disease (COVID-19) during the early outbreak period: a scoping review. Infect Dis Poverty 9: 29.

4. Fletcher RH, Fletcher SW (1983) Clinical epidemiology: a new discipline for an old art. Ann Intern Med 99: 401-403.

5. de Wit E, van Doremalen N, Falzarano D, Munster VJ (2016) SARS and MERS: recent insights into emerging coronaviruses. Nat Rev Microbiol 14: 523-534.

6. Ozili PK (2020) COVID-19 in Africa: socioeconomic impact, policy response and opportunities. Social Science Research Network.

7. Ighobor K (2020) AU study: COVID-19 could cost Africa $\$ 500$ billion, damage to tourism and aviation sectors. Africa Renewal.

8. Dawes DE (2020) The Political Determinants of Health. Johns Hopkins University Press, Baltimore, USA.

9. McKinsey \& Company (2020) Tackling COVID-19 in Africa.

10. Beaubien J (2020) The Coronavirus Crisis: How South Korea Reined in the Outbreak without Shutting Everything Down. National Public Radio, United States.

11. World Health Organization (2020) Maternal, newborn, child and adolescent health. Geneva, Switzerland.

12. Baltag V, Pachyna A, Hall J (2015) Global overview of school health services: data from 102 countries. Health Behav Policy Rev 2: 268283.

13. Valentijin PP, Schepman SM, Opheij W, Bruijnzeels MA (2013) Understanding integrated care: a comprehensive conceptual framework based on the integrative functions of primary care. Int J Integr Care 13: e010.

14. Wolfe I, Thompson M, Gill P, Tamburlini G, Blair M, et al. (2013) Health services for children in western Europe. Lancet 381: 12241234.

15. Martinez-Gonzalez NA, Djalali S, Tandjung R, Huber-Geismann F, Markun S, et al. (2014) Substitution of physicians by nurses in primary care: a systemic review and meta-analysis. BMC Health Serv Res 14: 214.

16. World Health Organization (2010) Pairing children with health services. The results of a survey on school health services in the WHO European Region. Europe.

17. Allensworth DD, Kolbe LJ (1987) The comprehensive school health program: exploring an expanded concept. J Sch Health 57: 409-412.

18. Smith MW, Ellis R (2020) Face Masks Reduce COVID Infection Risk by $65 \%$. WebMD Health News Brief. Oregon, United States.

19. Medical xpress (2020) Medical Xpress-Medical Research Advances and Health News. 
20. Andrew Brooks (2020) New Rutgers saliva test for corona virus gets FDA Approval. Rutgers Today.

21. Punch Health wise (2020) Senegal develops COVID-19 test kits for African countries. Idaho, Unites States.

22. Gupta S (2020) Corona virus: distancing, isolation, quarantine, lock down: what's the difference? The Ontario Educational Communications Authority, Canada.
23. Zeni MB (2019) Principles of epidemiology for advanced nursing practice: A population health perspective. Jones \& Bartlett Learning, Unites States.

24. Gordis L (2008) Epidemiology. Saunders, United States.

25. Edberg M (2015) Essentials of Health Behavior: Social and Behavioral Theory in Public Health. Jones \& Bartlett Learning, Unites States. 